\title{
Measuring the improvement in health-related quality of life using King's health questionnaire in non-obese and obese patients with lower urinary tract symptoms after alpha-adrenergic medication: a preliminary study
}

Jae Heon Kim¹, Hoon Choi², Hwa Yeon Sun', Seung Whan Doo', Jong Hyun Yoon', Won Jae Yang', Byung Wook Yoo ${ }^{3}$, Joyce Mary Kim ${ }^{4}$, Soon-Sun Kwon ${ }^{5}$, Eun Seop Song ${ }^{6}$, Hong Jun Lee ${ }^{7}$, Ik Sung Lim ${ }^{8}$ and Yun Seob Song ${ }^{1 *}$

\begin{abstract}
Background: The efficacy of medical treatment among obese men with lower urinary tract symptoms (LUTS) has been less clear, especially regarding the improvement of QoL. We aimed to investigate the difference in efficacy and consequent satisfaction of life quality after medical treatment of male LUTS according to obesity.

Methods: An 8-week prospective study was performed for a total of 140 patients $>50$ years old with International Prostate Symptom Scores (IPSS) $>12$ points and prostate volume $>20 \mathrm{~mL}$. Obesity was determined by either body mass index (BMI) or waist circumference (WC). Patients were divided into 2 groups according to BMI or WC. Patients received tamsulosin at a dose of $0.4 \mathrm{mg}$ daily for 8 weeks. The changes from baseline in the IPSS, maximal urinary flow rate (Qmax), post-void residual volume, questionnaire of quality of life (QoL), and King's Health Questionnaire $(\mathrm{KHQ})$ were analyzed.
\end{abstract}

Results: Of the 150 enrolled patients, 96 completed the study. Seventy-five patients (78.1\%) had BMl $\geq 23 \mathrm{~kg} / \mathrm{m}^{2}$, and 24 (25.0\%) had WC $>90 \mathrm{~cm}$. Overall, the IPSS, IPSS QoL, and total KHQ showed significant improvement. Obese $\left(\mathrm{BMI} \geq 23 \mathrm{~kg} / \mathrm{m}^{2}\right)$ and non-obese $\left(\mathrm{BMl}<23 \mathrm{~kg} / \mathrm{m}^{2}\right)$ both showed improvement of the IPSS and IPSS QoL scores, but only the obese (BMI $\left.\geq 23 \mathrm{~kg} / \mathrm{m}^{2}\right)$ group showed improvement of the total KHQ score $(P<0.001 \mathrm{vs}$. $P=0.55)$. Only the obese $(W C>90 \mathrm{~cm})$ group showed improvement of the IPSS and total KHQ scores $(P<0.001)$.

Conclusions: Our preliminary study showed the different efficacy of an alpha-blocker for improvement of LUTS and life quality according to obesity. Obese patients, defined by BMI or WC, showed the tendency toward a more favorable improvement of LUTS and life quality.

Trial registration: Current Controlled Trials 2010-058. Registered 2 September 2010 in Soonchunhyang Univeristy Hospital

Keywords: Alpha-blocker, Prostatic hyperplasia, Body mass index, Waist circumference

\footnotetext{
* Correspondence: yssong@schmc.ac.kr

'Department of Urology, Soonchunhyang University College of Medicine, Seoul Hospital, 59, Daesagwan-ro, Yongsan-gu, Seoul 140-743, The Republic of Korea

Full list of author information is available at the end of the article
} 


\section{Background}

Benign prostatic hyperplasia $(\mathrm{BPH}) /$ lower urinary tract symptoms (LUTS) is a common disease entity in older men and has a negative impact on quality of life (QoL) [1-3]. Obesity is also a common condition in older males and is related to LUTS $[1,3]$. As in Western countries, Korean men have a high prevalence of symptomatic $\mathrm{BPH}$ as they age, with a prevalence of $10.6 \%-31 \%$ in men $>50$ years old $[2,4]$. Several studies have reported a significant relationship between LUTS and obesity $[3,5,6]$. Considering the objective evidence of a negative effect of both LUTS [7-13] and obesity [14] on QoL, LUTS plus obesity may result in a greater deterioration of QoL.

Among the alpha blockers, tamsulosin is one of the most commonly recommended because of its efficacy, safety, and tolerability [15]. The King's Health Questionnaire (KHQ) is a validated tool to measure the QoL in patients with LUTS [9]. Although the KHQ was developed originally for female urge incontinence, validity has been proven in studies that dealt with LUTS and healthrelated quality of life (HRQoL) in both sexes [9,16-19].

To date, efficacy of medical treatment among obese men with LUTS has been less clear, especially regarding the improvement of QoL within specific domains. Recently, Lee et al. [14] reported that alpha-blockers have a greater efficacy in improvement of LUTS when used in obese men. The main presumed hypothesis for this difference is that obese men have a greater level of sympathetic activity, which is suspected to be sensitive to alpha-blockers [20,21].

The main purpose of this preliminary study is to investigate the improvement of LUTS and QoL in different groups (obese and non-obese).

\section{Methods}

\section{Study design}

An eight-week prospective study was conducted between March 2010 and May 2011. The study was approved by the institutional review board of Soonchunhyang University Hospital.

At the initial visit, anthropometric parameters were evaluated, including weight, height, and waist circumference. Additional parameters measured included urinalysis, serum prostate-specific antigen [22], maximal urinary flow rate (Qmax), and post-void residual volume (PVR). Transrectal ultrasonography was also performed. At the initial and final visits, the International Prostate Symptom Score (IPSS) and KHQ were measured.

BMI was calculated as the body weight in kilograms divided by the square of the height in meters. After the first evaluation, eligible patients were treated with tamsulosin at a dose of $0.4 \mathrm{mg}$ for 8 weeks. At each visit, adverse events were recorded.

Serum PSA tests were performed using the automated chemiluminescent microparticle immunoassay analyzer
Architect i2000 (Abbott Diagnostic Laboratories, Abbott Park, IL, USA). The prostate was measured in three dimensions by transrectal ultrasonography using an 8.0-MHz rectal probe (GE Healthcare, LOGIQ P6-PRO, Little Chalfont, UK), and prostate volume (PV) was estimated using a modification of the prolate ellipsoid formula and recorded in $\mathrm{cm}^{3}(0.523$ [length $(\mathrm{cm}) \times$ width $(\mathrm{cm}) \times$ height $(\mathrm{cm})])$.

Acquisition of questionnaire data was performed with face-to-face interviews conducted by one investigator with all study participants using a structured questionnaire. The severity of LUTS was measured using the IPSS, which is based on the American Urological Association [23] symptom index with one additional question on QoL, and is the most widely used objective assessment of LUTS.

The KHQ consists of 8 categories, including general health perceptions, impact on life, role limitations, physical/ social limitation, personal relationships, emotions, sleep/ energy, and incontinence severity measures. The KHQ has been validated in a Korean version [24].

\section{Subjects}

A total of 150 patients who visited the Department of Urology at Soonchunhyang University and provided informed consent were included in this study. Inclusion criteria were male $\geq 40$ years of age, no history of prior treatment of $\mathrm{BPH} / \mathrm{LUTS}$, total IPSS $\geq 8$, prostate volume $>20 \mathrm{~mL}$ as determined by transrectal ultrasound, no relevant medical history, and underlying comorbidities. Exclusion criteria were history of neurogenic bladder dysfunction, history of prostate or bladder cancer, treatment history of acute or chronic urinary retention within the previous 3 months, treatment history of acute or chronic prostatitis within the previous 3 months, PSA levels $>0.10 \mathrm{ng} / \mathrm{mL}$, and history of urinary tract infection or bladder stones.

All patients were divided into 2 groups, non-obese $\left(\mathrm{BMI}<23 \mathrm{~kg} / \mathrm{m}^{2}\right)$ and obese $\left(\mathrm{BMI} \geq 23 \mathrm{~kg} / \mathrm{m}^{2}\right)$, according to the Asia-Pacific obesity criteria [25]. For additional analysis, we also categorized patients into 2 groups based on waist circumference (WC), normal waist $(\leq 90 \mathrm{~cm})$ and central obesity $(>90 \mathrm{~cm})$.

\section{Power calculation}

Sample size was not calculated because its being a preliminary study.

\section{Statistical analysis}

The primary outcome measurement was the degree of change of KHQ in the two groups, and secondary outcome measurement was the degree of change of IPSS in the two groups. All data are presented as mean \pm SD. Statistical analysis was performed using SPSS (version 21.0; Chicago, IL, USA). Changes from baseline in total 
IPSS, QoL scores, and KHQ scores were analyzed using Wilcoxon signed-rank test. A P value $<0.05$ was considered significant.

\section{Results}

Of the 140 enrolled patients, 96 completed the study. Fifty four patients discontinued the trial. Of these, 22 were lost to follow-up, 14 refused to complete the final questionnaires, and 18 patients discontinued the medication because of low efficacy ( 9 patients) or adverse events (9 patients) (Figure 1).

The basic characteristics, including age, PSA, PV, Qmax, total IPSS, and KHQ questionnaire are described in Table 1. Between the obese group (BMI $\geq 23 \mathrm{~kg} / \mathrm{m}^{2}$ ) and non-obese group $\left(\mathrm{BMI}<23 \mathrm{~kg} / \mathrm{m}^{2}\right)$, no significant difference occurred among the variables. Between the central obesity group (WC > $90 \mathrm{~cm}$ ) and non-central obesity group (WC $\leq 90 \mathrm{~cm}$ ), no significant difference occurred among the variables except age.

After 8 weeks treatment with tamsulosin, overall improvement was seen in the total IPSS and IPSS QoL $(\mathrm{P}<0.001)$ (Table 2). Total KHQ scores also improved after treatment $(\mathrm{P}<0.001)$. Among the domains, general health, impact on life, role limitations, physical limitation, emotions, sleep/energy, and incontinence severity were improved or significantly improved. However, social limitation and personal relationships did not show improvement after treatment (Table 2).
In subgroup analysis, the non-obese group showed no improvement in total KHQ $(\mathrm{P}=0.055)$ (Table 3). Among the KHQ domains, the obese group showed improvement only in general health $(\mathrm{P}=0.025)$, impact on life $(P=0.020)$, and emotions $(P=0.047)$. The obese group showed improvement in total KHQ $(\mathrm{P}<0.001)$ (Table 3). Among the KHQ domains, the obese group showed improvement in general health $(\mathrm{P}<0.001)$, impact on life $(\mathrm{P}<0.001)$, role limitations $(\mathrm{P}=0.001)$, physical limitation $(\mathrm{P}<0.001)$, and emotions $(\mathrm{P}<0.001)$. The comparison of improvement of IPSS and KHQ revealed that obesity group showed significant greater improvement in total IPSS, physical limitation, and sleep/energy (Table 4).

In other subgroup analysis, the non-central obesity group showed no improvement in total IPSS, IPSS QoL, and total KHQ (Table 4). Among the KHQ domains, the non-central obesity group showed improvement only in general health $(\mathrm{P}=0.020)$ and impact on life $(\mathrm{P}=0.032)$. The central obesity group showed improvement in total IPSS, IPSS QoL, and total KHQ (Table 5). Among the KHQ domains, the central obesity group showed improvement in general health $\mathrm{P}<0.001)$, impact on life $(\mathrm{P}<0.001)$, role limitations $(\mathrm{P}<0.001)$, physical limitation $(\mathrm{P}=0.002)$, personal relationships $(\mathrm{P}=0.029)$, emotions $(\mathrm{P}<0.001)$, and sleep/energy $(\mathrm{P}=0.024)$. The comparison of improvement of IPSS and KHQ revealed that central obesity group showed significant greater improvement in total IPSS, impact of life, and sleep/energy (Table 5).

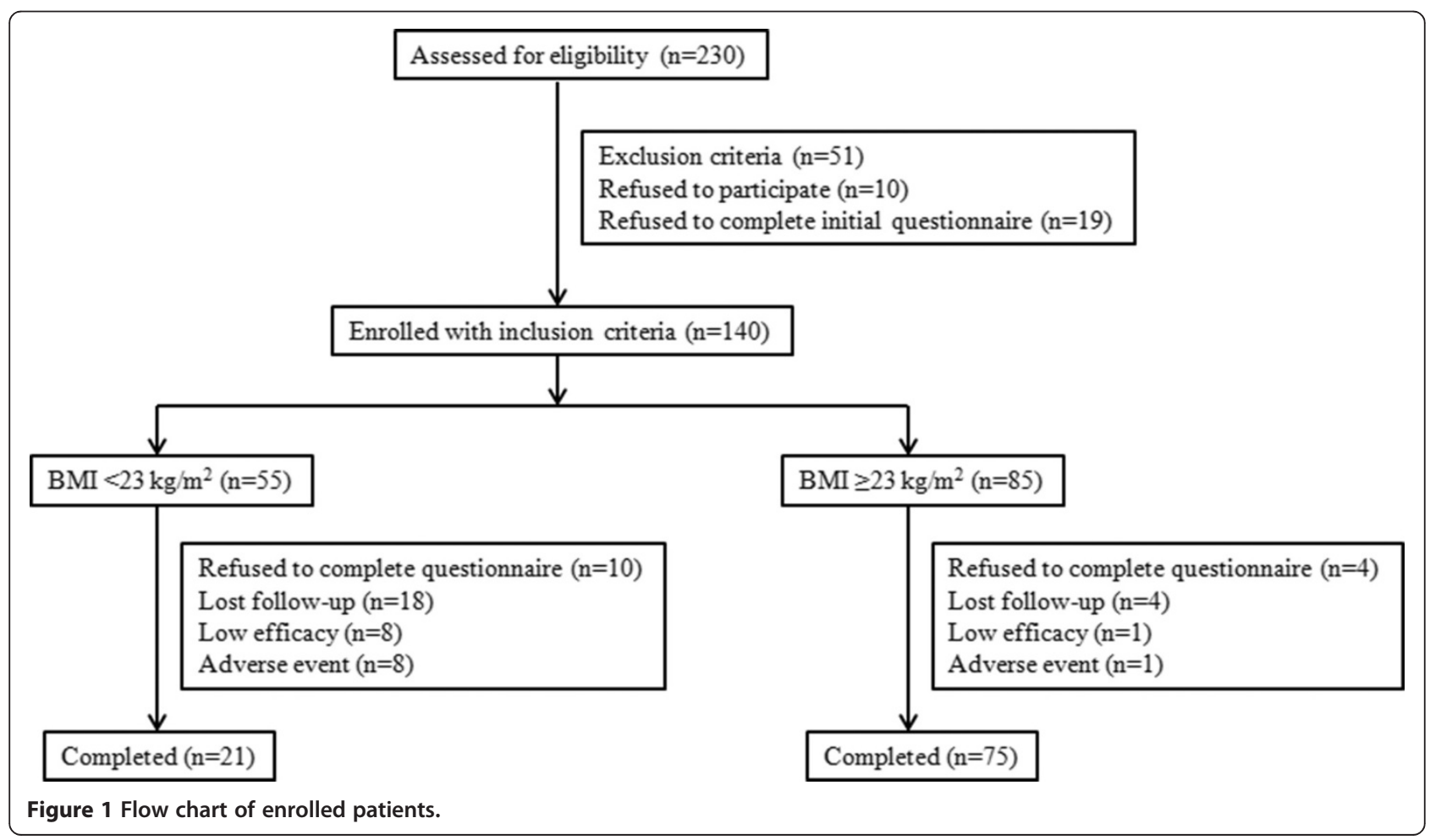


Table 1 Basic characteristics of participants

\begin{tabular}{|c|c|c|c|c|c|c|}
\hline & $\mathrm{BMI}<23$ & $\mathrm{BMI} \geq 23$ & $P$ value & $W C \leq 90$ & $W C>90$ & $P$ value \\
\hline No & 21 & 75 & & 72 & 24 & \\
\hline Age & $61.25 \pm 9.80$ & $61.48 \pm 7.09$ & 0.982 & $60.58 \pm 7.60$ & $64.20 \pm 7.54$ & 0.045 \\
\hline PSA & $2.12 \pm$ & $2.04 \pm$ & 0.231 & $2.13 \pm$ & $1.98 \pm$ & 0.312 \\
\hline PV & $31.12 \pm 10.14$ & $34.23 \pm 8.71$ & 0.042 & $32.31 \pm 9.81$ & $33.23 \pm 10.21$ & 0.218 \\
\hline Qmax & $12.32 \pm 2.21$ & $13.25 \pm 1.75$ & 0.134 & $11.46 \pm 1.89$ & $13.33 \pm 2.34$ & 0.185 \\
\hline \multicolumn{7}{|l|}{ IPSS questionnaire } \\
\hline Total IPSS & $14.90 \pm 7.58$ & $13.41 \pm 6.79$ & 0.388 & $15.00 \pm 7.57$ & $13.31 \pm 6.74$ & 0.308 \\
\hline IPSS QoL & $3.47 \pm 1.21$ & $3.54 \pm 1.22$ & 0.830 & $3.56 \pm 1.40$ & $3.51 \pm 1.15$ & 0.864 \\
\hline \multicolumn{7}{|l|}{ KHQ questionnaire } \\
\hline General health & $41.66 \pm 18.25$ & $47.66 \pm 23.67$ & 0.286 & $47.91 \pm 26.49$ & $45.83 \pm 21.39$ & 0.698 \\
\hline Impact on life & $53.91 \pm 30.65$ & $58.60 \pm 30.40$ & 0.534 & $58.27 \pm 28.20$ & $57.35 \pm 31.22$ & 0.898 \\
\hline Role limitations & $25.29 \pm 33.45$ & $28.77 \pm 31.98$ & 0.664 & $33.20 \pm 37.91$ & $26.28 \pm 30.10$ & 0.364 \\
\hline Physical limitation & $29.24 \pm 31.45$ & $27.44 \pm 30.08$ & 0.811 & $33.20 \pm 34.26$ & $26.05 \pm 28.79$ & 0.318 \\
\hline Social limitation & $22.19 \pm 31.81$ & $16.71 \pm 25.48$ & 0.411 & $18.03 \pm 24.83$ & $17.87 \pm 27.59$ & 0.980 \\
\hline Personal relationships & $21.71 \pm 37.96$ & $25.39 \pm 32.24$ & 0.724 & $24.90 \pm 35.34$ & $24.55 \pm 32.84$ & 0.972 \\
\hline Emotions & $25.90 \pm 31.06$ & $27.52 \pm 25.83$ & 0.808 & $31.91 \pm 29.15$ & $25.59 \pm 26.12$ & 0.321 \\
\hline Sleep/Energy & $26.08 \pm 29.49$ & $21.02 \pm 26.64$ & 0.454 & $18.67 \pm 24.13$ & $23.28 \pm 28.22$ & 0.475 \\
\hline Incontinence & $14.14 \pm 27.47$ & $9.85 \pm 14.73$ & 0.343 & $16.50 \pm 21.31$ & $8.89 \pm 16.76$ & 0.076 \\
\hline Total KHQ & $251.88 \pm 223.71$ & $254.88 \pm 171.03$ & 0.947 & $274.31 \pm 198.90$ & $247.53 \pm 178.02$ & 0.537 \\
\hline
\end{tabular}

Adverse events were reported in 9 patients (6.0\%) and included dizziness (3.3\%), postural hypotension (1.3\%), and gastric discomfort (1.3\%).

\section{Discussion}

When obese patients with BPH have LUTS, a larger prostate is presumed to be one of the causes. The prostate grows faster in obese than in non-obese patients [26-28].

Many clinical studies have focused on prostate size or PSA in obese patients, but few studies have focused on the treatment outcome, including QoL, in obese patients. Although several studies have used the IPSS-QoL index to present the treatment outcome in obese patients

Table 2 Differences in IPSS and KHQ before and after treatment

\begin{tabular}{|c|c|c|c|c|c|}
\hline \multirow[b]{2}{*}{ IPSS } & \multirow[t]{2}{*}{ Mean difference } & \multirow[t]{2}{*}{ SD } & \multicolumn{2}{|c|}{$95 \% \mathrm{Cl}$} & \multirow[t]{2}{*}{$P$ value } \\
\hline & & & & & \\
\hline IPSS questionnaire & 3.521 & 6.764 & 2.150 & 4.891 & $<0.001$ \\
\hline QoL & 1.011 & 1.487 & .701 & 1.321 & $<0.001$ \\
\hline \multicolumn{6}{|l|}{$\mathrm{KHQ}$} \\
\hline General health & 13.281 & 25.380 & 8.139 & 18.424 & $<0.001$ \\
\hline Impact on life & 18.417 & 32.513 & 11.829 & 25.004 & $<0.001$ \\
\hline Role limitations & 10.302 & 26.954 & 4.841 & 15.764 & $<0.001$ \\
\hline Physical limitation & 9.490 & 26.417 & 4.137 & 14.842 & 0.001 \\
\hline Social limitation & 3.323 & 24.418 & -1.625 & 8.271 & 0.186 \\
\hline Personal relationships & 5.283 & 24.118 & -1.365 & 11.931 & 0.117 \\
\hline Emotions & 9.656 & 19.902 & 5.624 & 13.689 & $<0.001$ \\
\hline Sleep/Energy & 4.632 & 22.549 & .038 & 9.225 & 0.048 \\
\hline Incontinence & 3.010 & 14.141 & .145 & 5.876 & 0.040 \\
\hline Total KHQ & 76.167 & 144.346 & 46.920 & 105.414 & $<0.001$ \\
\hline
\end{tabular}


Table 3 Differences in IPSS and KHQ before and after treatment according to BMI

\begin{tabular}{|c|c|c|c|c|c|c|}
\hline & \multicolumn{3}{|c|}{$\mathrm{BMI}<23$} & \multicolumn{3}{|c|}{$\mathrm{BMI} \geq 23$} \\
\hline & Mean difference & SD & $P$ value & Mean difference & SD & $P$ value \\
\hline \multicolumn{7}{|l|}{ IPSS questionnaire } \\
\hline Total IPSS & 5.571 & 7.928 & .004 & 2.947 & 6.341 & $<0.001$ \\
\hline QoL & 1.105 & 1.243 & .001 & .986 & 1.552 & $<0.001$ \\
\hline \multicolumn{7}{|l|}{ KHQ questionnaire } \\
\hline General health & 10.714 & 20.266 & .025 & 14.000 & 26.712 & $<0.001$ \\
\hline Impact on life & 20.619 & 37.377 & .020 & 17.800 & 31.269 & $<0.001$ \\
\hline Role limitations & 9.381 & 27.006 & .127 & 10.560 & 27.116 & 0.001 \\
\hline Physical limitation & 3.190 & 34.945 & .680 & 11.253 & 23.483 & $<0.001$ \\
\hline Social limitation & 8.429 & 27.770 & .180 & 1.893 & 23.400 & 0.486 \\
\hline Personal relationships & 5.556 & 37.250 & .666 & 5.227 & 21.101 & 0.108 \\
\hline Emotions & 10.571 & 22.892 & .047 & 9.400 & 19.146 & $<0.001$ \\
\hline Sleep/Energy & 7.048 & 25.488 & .220 & 3.946 & 21.785 & .124 \\
\hline Incontinence & 6.524 & 23.159 & .211 & 2.027 & 10.357 & .094 \\
\hline Total KHQ & 79.762 & 179.641 & .055 & 75.160 & 134.246 & $<0.001$ \\
\hline
\end{tabular}

$[14,29,30]$, the IPSS-QoL is not a disease-specific questionnaire. Rather, it represents the state of generalized HRQoL in men with LUTS.

The most prominent feature of our study was use of the KHQ questionnaire, a disease-specific HRQoL instrument for the evaluation of patients with LUTS, overactive bladder, and urinary incontinence [9,16-19]. The KHQ consists of nine domains. Seven of the domains include multiple questions including role limitations, physical limitations, social limitations, personal relationships, emotions, sleep/energy, and incontinence severity measures.
Our study revealed that comparison of improvement of IPSS QoL according to BMI and WC showed no significant difference. However, the comparison of improvement KHQ including impact on life, physical limitation, impact of life, and sleep/energy showed significant difference. Although improvement of total KHQ showed no significant difference, several domains of KHQ showed significant differences.

Although some controversies exist regarding the relationship between the severity of LUTS and obesity, obese patients usually have more severe LUTS than

Table 4 Differences in IPSS and KHQ before and after treatment according to waist circumference

\begin{tabular}{|c|c|c|c|c|c|c|}
\hline & \multicolumn{3}{|c|}{$W C<90$} & \multicolumn{3}{|c|}{$W C \geq 90$} \\
\hline & Mean difference & SD & $P$ value & Mean difference & SD & $P$ value \\
\hline \multicolumn{7}{|l|}{ IPSS questionnaire } \\
\hline Total IPSS & 2.667 & 7.191 & .082 & 3.806 & 6.643 & $<0.001$ \\
\hline QoL & .957 & 1.637 & .010 & 1.029 & 1.445 & $<0.001$ \\
\hline \multicolumn{7}{|l|}{ KHQ questionnaire } \\
\hline General health & 14.583 & 28.473 & .020 & 12.847 & 24.464 & $<0.001$ \\
\hline Impact on life & 15.292 & 32.742 & .032 & 19.458 & 32.600 & $<0.001$ \\
\hline Role limitations & 8.250 & 38.649 & .307 & 10.986 & 22.053 & $<0.001$ \\
\hline Physical limitation & 8.333 & 28.448 & .165 & 9.875 & 25.904 & 0.002 \\
\hline Social limitation & .083 & 20.581 & .984 & 4.403 & 25.610 & 0.149 \\
\hline Personal relationships & -4.714 & 21.084 & .418 & 8.872 & 24.369 & 0.029 \\
\hline Emotions & 3.667 & 18.253 & .335 & 11.653 & 20.147 & $<0.001$ \\
\hline Sleep/Energy & -1.458 & 14.623 & .630 & 6.690 & 24.404 & 0.024 \\
\hline Incontinence & 3.000 & 12.487 & .251 & 3.014 & 14.733 & 0.087 \\
\hline Total KHQ & 52.333 & 165.817 & .136 & 84.111 & 136.806 & $<0.001$ \\
\hline
\end{tabular}


Table 5 Comparison of the differences in IPSS and KHQ according to BMI and waist circumference

\begin{tabular}{|c|c|c|c|c|c|c|}
\hline & $\mathrm{BMI}<23$ & $\mathrm{BMI} \geq 23$ & $P$ value & $W C \leq 90$ & WC > 90 & $P$ value \\
\hline \multicolumn{7}{|l|}{ IPSS questionnaire } \\
\hline$\triangle$ Total IPSS & $3.37 \pm 6.17$ & $6.00 \pm 7.66$ & 0.041 & $2.87 \pm 7.18$ & $4.30 \pm 6.38$ & 0.028 \\
\hline$\triangle I P S S$ QoL & $0.96 \pm 1.52$ & $1.00 \pm 1.22$ & 0.830 & $0.79 \pm 1.79$ & $1.02 \pm 1.34$ & 0.231 \\
\hline \multicolumn{7}{|l|}{ KHQ questionnaire } \\
\hline$\Delta$ General health & $10.71 \pm 20.26$ & $14.00 \pm 26.71$ & 0.286 & $14.58 \pm 28.47$ & $12.84 \pm 24.46$ & 0.321 \\
\hline$\Delta$ Impact on life & $17.76 \pm 31.12$ & $20.06 \pm 37.19$ & 0.052 & $15.26 \pm 32.53$ & $19.42 \pm 32.46$ & 0.028 \\
\hline$\Delta$ Role limitations & $10.61 \pm 27.10$ & $9.48 \pm 27.05$ & 0.564 & $8.30 \pm 38.54$ & $11.06 \pm 22.11$ & 0.356 \\
\hline$\triangle$ Physical limitation & $3.16 \pm 35.06$ & $11.28 \pm 23.50$ & 0.032 & $8.30 \pm 28.54$ & $9.91 \pm 25.93$ & 0.068 \\
\hline$\Delta$ Social limitation & $4.20 \pm 22.84$ & $3.16 \pm 27.08$ & 0.347 & $4.01 \pm 20.62$ & $4.39 \pm 25.64$ & 0.780 \\
\hline$\Delta$ Personal relationships & $5.71 \pm 27.96$ & $5.39 \pm 22.24$ & 0.561 & $5.09 \pm 22.05$ & $4.71 \pm 28.32$ & 0.814 \\
\hline$\Delta$ Emotions & $9.47 \pm 19.19$ & $10.57 \pm 22.87$ & 0.706 & $10.91 \pm 18.41$ & $11.76 \pm 20.14$ & 0.415 \\
\hline$\Delta$ Sleep/Energy & $3.98 \pm 21.63$ & $7.11 \pm 25.48$ & 0.031 & $3.21 \pm 14.61$ & $6.68 \pm 24.23$ & 0.035 \\
\hline Alncontinence & $19.69 \pm 24.66$ & $18.35 \pm 24.96$ & 0.381 & $18.43 \pm 24.99$ & $19.72 \pm 24.64$ & 0.451 \\
\hline$\Delta$ Total KHQ & $75.20 \pm 134.25$ & $79.87 \pm 179.59$ & 0.061 & $52.47 \pm 165.90$ & $84.14 \pm 136.77$ & 0.071 \\
\hline
\end{tabular}

non-obese patients [29,30]. Possible reasons for this phenomenon are lower testosterone concentrations, lower serum globulin-binding protein levels, and greater prostate volumes in obese patients [31], as well as increased estrogen levels and increased free and total estradiol concentrations [32,33].

Our data demonstrate that the baseline total IPSS showed no significant difference between the obese and non-obese groups or central obesity and non-central obesity groups. This is mainly due to our lower IPSS inclusion criteria of more than 8 points total on the IPSS. We lowered the criteria for the IPSS because patients scoring higher on the IPSS could bias the results by showing more satisfaction with treatment.

Our data showed a more favorable treatment outcome in obese patients and those with central obesity. Although an improvement in the total IPSS was demonstrated in both obese and non-obese patients, the improvement in the total IPSS was only demonstrated in patients with central obesity. Improvement in total KHQ scores was demonstrated only in obese patients and patients with central obesity.

Greater estrogen levels in old age and obesity induce lower testosterone levels and may affect prostate cell growth [32]. Enlarged adipose tissue can secrete numerous hormones and proteins that influence fat metabolism $[34,35]$, and leptin stimulates the cellular proliferation of $\mathrm{BPH}[36,37]$.

Besides an enlarged prostate, obese patients have increased sympathetic tone, which is suspected to be the main reason alpha blockers could have a greater impact in obese patients. Increased sympathetic tone can result in LUTS and subjective voiding complaints [19]. In particular, abdominal obesity increases the estrogen-to- androgen ratio and may increase sympathetic nervous system activity, both of which are known to influence the development of $\mathrm{BPH}$ and the severity of LUTS [18]. In our study, obese patients showed improvement in 5 domains of the KHQ, but central obesity patients showed improvement in 7 domains of the KHQ. This result implies that obesity, especially central obesity, which is regarded as visceral obesity, could impact treatment outcomes. The main reason for this result is that obesity, and especially visceral adiposity, is closely related to sympathetic overactivity $[38,39]$. The whole body norepinephrine spillover rate is known to be quantitatively linked with waist circumference [17,31], and sympathetic nerve firing rates measured by microneurography have been reported to be $55 \%$ higher in men with visceral adiposity than in men with only subcutaneous obesity.

Sympathetic activity is increased in obese men and may be related to BPH/LUTS by a common link between norepinephrine and alpha-1 adrenoceptors [38,39]. Although general improvement of LUTS and KHQ were observed in this study, the obesity and central obesity groups showed more improvement in the IPSS and KHQ.

This study has several limitations. First, the study design has a relatively short follow-up period. However, 8 weeks is sufficient to judge the clinical outcome of alpha blockers. Moreover, the KHQ is a relatively long questionnaire and takes a long time to perform, which reduces patient compliance. Although the acquisition of questionnaire was performed by one special interviewer, a lot of patients showed negative response to the KHQ in our study. The most common reason for this negative response is that it takes quite a long time. This is why we did not perform an additional KHQ at 4 weeks. Second, this study has a relatively 
small size. However, considering the increasing prevalence of concomitant medical diseases, the availability of eligible patients is limited. This was a pilot; a preliminary study, and subsequent prospective study is needed.

\section{Conclusions}

Obese or central obesity patients with LUTS showed a better health-related quality of life than non-obese or non-centrally obese patients with LUTS after alpha-adrenergic medication. Therefore, alpha-adrenergic medication can be recommended to obese patients with LUTS preferentially for the improvement of quality of life.

\section{Competing interest}

The authors declare that they have no competing interest.

\section{Authors' contributions}

JHK and YSS contributed with the conception and design of the study and drafted the manuscript, JHK, HC, SHY, SWD, WJY, BWY, JHY and MJK collected data, SSK performed the statistical analyses, and ESS, HJL, ISL, YSS have contributed on the critical revision of this manuscript. All authors read and approved the final manuscript.

\section{Acknowledgment}

This research was supported by Research Program through the National Research Foundation of Korea (NRF) funded by the Ministry of Education, Science and Technology (2012-R1A1A2039317) and Soonchunhang University Research Fund.

\section{Author details}

'Department of Urology, Soonchunhyang University College of Medicine, Seoul Hospital, 59, Daesagwan-ro, Yongsan-gu, Seoul 140-743, The Republic of Korea. ${ }^{2}$ Department of Urology, Korea University College of Medicine, Ansan Hospital, Ansan, Korea. ${ }^{3}$ Department of Family Medicine,

Soonchunhyang University School of Medicine, Seoul, Korea. ${ }^{4}$ International Clinic Center, Soonchunhyang University Hospital, Seoul, Korea. ${ }^{5}$ Biomedical Research Institute, Seoul National University Bundang Hospital, Seongnam, South Korea. ${ }^{6}$ Department of Obstetrics and Gynecology, Inha University School of Medicine, Incheon, Korea. ${ }^{7}$ Medical Research Institute, Chung-Ang University College of Medicine, Seoul, Korea. ${ }^{8}$ Department of Industrial Management and Engineering, Namseoul University College of Engineering, Cheonan, Korea.

Received: 24 April 2014 Accepted: 31 July 2014

Published: 6 August 2014

\section{References}

1. Lepor H: Phase III multicenter placebo-controlled study of tamsulosin in benign prostatic hyperplasia. Tamsulosin Investigator Group. Urology 1998, 51:892-900.

2. Park YHC MK: The prevalence of clinical benign prostatic hyperplasia and lower urinary tract symptoms in South-East Korea: a community-based study. J Pusan Natl Univ Hosp 2001, 9:141-157.

3. Giuliano F: Lower urinary tract symptoms and sexual dysfunction: a common approach. BJU Int 2008, 97(Suppl 3):22-26.

4. Lee MWL MH: The prevalence of benign prostatic hyperplasia in self-referral populations over aged 50. Korean J Urol 1996, 37:263-267.

5. Lee $E$, Lee $C$ : Clinical comparison of selective and non-selective alpha 1A-adrenoreceptor antagonists in benign prostatic hyperplasia: studies on tamsulosin in a fixed dose and terazosin in increasing doses. Br J Urol 1997, 80:606-611.

6. Giuliano F: Impact of medical treatments for benign prostatic hyperplasia on sexual function. BJU Int 2006, 97(Suppl 2):34-38. discussion 44-35.

7. Na YJ, Guo YL, Gu FL: Clinical comparison of selective and non-selective alpha $1 \mathrm{~A}$-adrenoceptor antagonists for bladder outlet obstruction associated with benign prostatic hyperplasia: studies on tamsulosin and terazosin in Chinese patients. The Chinese Tamsulosin Study Group. J Med 1998, 29:289-304.
8. McVary KT, Roehrborn CG, Avins AL, Barry MJ, Bruskewitz RC, Donnell RF, Foster HE Jr, Gonzalez CM, Kaplan SA, Penson DF, Ulchaker JC, Wei JT: Update on AUA guideline on the management of benign prostatic hyperplasia. J Urol 2011, 185:1793-1803.

9. Watson V, Ryan M, Brown CT, Barnett G, Ellis BW, Emberton M: Eliciting preferences for drug treatment of lower urinary tract symptoms associated with benign prostatic hyperplasia. J Urol 2004, 172(6 Pt 1):2321-2325.

10. Li NC, Chen S, Yang XH, Du LD, Wang JY, Na YQ: Efficacy of low-dose tamsulosin in chinese patients with symptomatic benign prostatic hyperplasia. Clin Drug Investig 2003, 23:781-787.

11. Madersbacher S, Alivizatos G, Nordling J, Sanz CR, Emberton M, de la Rosette JJ: EAU 2004 guidelines on assessment, therapy and follow-up of men with lower urinary tract symptoms suggestive of benign prostatic obstruction (BPH guidelines). Eur Urol 2004, 46:547-554.

12. Patrick DL, Martin ML, Bushnell DM, Yalcin I, Wagner TH, Buesching DP. Quality of life of women with urinary incontinence: further development of the incontinence quality of life instrument (I-QOL). Urology 1999, 53:71-76.

13. Barry MJ, Williford WO, Chang Y, Machi M, Jones KM, Walker-Corkery E, Lepor $\mathrm{H}$ : Benign prostatic hyperplasia specific health status measures in clinical research: how much change in the American Urological Association symptom index and the benign prostatic hyperplasia impact index is perceptible to patients? J Urol 1995, 154:1770-1774.

14. Lee SH, Oh CY, Park KK, Chung MS, Yoo SJ, Chung BH: Comparison of the clinical efficacy of medical treatment of symptomatic benign prostatic hyperplasia between normal and obese patients. Asian J Androl 2011, 13:728-731.

15. Maldonado-Avila M, Manzanilla-Garcia HA, Sierra-Ramirez JA, Carrillo-Ruiz JD, Gonzalez-Valle JC, Rosas-Nava E, Guzman-Esquivel J, Labra-Salgado IR: A comparative study on the use of tamsulosin versus alfuzosin in spontaneous micturition recovery after transurethral catheter removal in patients with benign prostatic growth. Int Urol Nephrol 2014, 46:687-690.

16. Okamura K, Usami T, Nagahama K, Maruyama S, Mizuta E: "Quality of life" assessment of urination in elderly Japanese men and women with some medical problems using International Prostate Symptom Score and King's Health Questionnaire. Eur Urol 2002, 41:411-419.

17. Okamura K, Usami T, Nagahama K, Maruyama S, Mizuta E: The relationships among filling, voiding subscores from International Prostate Symptom Score and quality of life in Japanese elderly men and women. Eur Urol 2002, 42:498-505.

18. Reese PR, Pleil AM, Okano GJ, Kelleher CJ: Multinational study of reliability and validity of the King's Health Questionnaire in patients with overactive bladder. Qual Life Res 2003, 12:427-442.

19. Uemura S, Homma Y: Reliability and validity of King's Health Questionnaire in patients with symptoms of overactive bladder with urge incontinence in Japan. Neurourol Urodyn 2004, 23:94-100.

20. Ahima RS, Stanley TL, Khor VK, Zanni MV, Grinspoon SK: Estrogen sulfotransferase is expressed in subcutaneous adipose tissue of obese humans in association with TNF-alpha and SOCS3. J Clin Endocrinol Metab 2011, 96:E1153-E1158.

21. Hillebrand S, de Mutsert R, Christen T, Maan AC, Jukema JW, Lamb HJ, de Roos A, Rosendaal FR, den Heijer M, Swenne CA: Body fat, especially visceral fat, is associated with electrocardiographic measures of sympathetic activation. Obesity (Silver Spring) 2014, 22:1553-1559.

22. Fedorchenko PM, Zhila W, Sapsai VI, Volkov GP, Chernenko PS: [Postgraduate training and ways of improving it in a department of urology]. Klin Khir 1986, 10:48-50

23. Suzigan S, Drut R, Faria P, Argani P, De Marzo AM, Barbosa RN, Mello Denadai ER, Martins-Filho J, Martucci RC, Bauab T Jr: Xp11 translocation carcinoma of the kidney presenting with multilocular cystic renal cell carcinoma-like features. Int J Surg Pathol 2007, 15:199-203.

24. Oh SJ, Ku JH: Comparison of three disease-specific quality-of-life questionnaires (Bristol Female Lower Urinary Tract Symptoms, Incontinence Quality of Life and King's Health Questionnaire) in women with stress urinary incontinence. Scand J Urol Nephrol 2007, 41(1):66-71

25. Kanazawa M, Yoshiike N, Osaka T, Numba Y, Zimmet P, Inoue S: Criteria and classification of obesity in Japan and Asia-Oceania. World Rev Nutr Diet 2005, 94:1-12. 
26. Hammarsten J, Hogstedt B: Clinical, anthropometric, metabolic and insulin profile of men with fast annual growth rates of benign prostatic hyperplasia. Blood Press 1999, 8:29-36.

27. Hammarsten J, Hogstedt B, Holthuis N, Mellstrom D: Components of the metabolic syndrome-risk factors for the development of benign prostatic hyperplasia. Prostate Cancer Prostatic Dis 1998, 1(3):157-162.

28. Ozden C, Ozdal OL, Urgancioglu G, Koyuncu H, Gokkaya S, Memis A: The correlation between metabolic syndrome and prostatic growth in patients with benign prostatic hyperplasia. Eur Urol 2007, 51:199-203. discussion 204-196.

29. Mondul AM, Giovannucci E, Platz EA: A prospective study of obesity, and the incidence and progression of lower urinary tract symptoms. J Urol 2014, 191:715-721.

30. Penson DF, Munro HM, Signorello LB, Blot WJ, Fowke JH, Urologic Diseases in America P: Obesity, physical activity and lower urinary tract symptoms: results from the Southern Community Cohort Study. J Urol 2011, 186:2316-2322.

31. Lee S, Min HG, Choi SH, Kim YJ, Oh SW, Park Y, Kim SS: Central obesity as a risk factor for prostatic hyperplasia. Obesity (Silver Spring) 2006, 14:172-179.

32. Matsuda T, Abe H, Suda K: [Relation between benign prostatic hyperplasia and obesity and estrogen]. Rinsho Byori 2004, 52:291-294.

33. Pasquali R, Casimirri F, Cantobelli S, Melchionda N, Morselli Labate AM, Fabbri R, Capelli M, Bortoluzzi L: Effect of obesity and body fat distribution on sex hormones and insulin in men. Metab Clin Exp 1991, 40:101-104.

34. Considine RV, Sinha MK, Heiman ML, Kriauciunas A, Stephens TW, Nyce MR, Ohannesian JP, Marco CC, McKee LJ, Bauer TL, Caro JF: Serum immunoreactive-leptin concentrations in normal-weight and obese humans. N Engl J Med 1996, 334:292-295.

35. Haque WA, Garg A: Adipocyte biology and adipocytokines. Clin Lab Med 2004, 24:217-234.

36. Dahle SE, Chokkalingam AP, Gao YT, Deng J, Stanczyk FZ, Hsing AW: Body size and serum levels of insulin and leptin in relation to the risk of benign prostatic hyperplasia. J Urol 2002, 168:599-604.

37. Hoon Kim J, Lee SY, Myung SC, Kim YS, Kim TH, Kim MK: Clinical significance of the leptin and leptin receptor expressions in prostate tissues. Asian J Androl 2008, 10:923-928.

38. Alvarez GE, Beske SD, Ballard TP, Davy KP: Sympathetic neural activation in visceral obesity. Circulation 2002, 106:2533-2536.

39. Eckel RH, Grundy SM, Zimmet PZ: The metabolic syndrome. Lancet 2005, 365:1415-1428.

\section{doi:10.1186/1471-2490-14-60}

Cite this article as: Kim et al:: Measuring the improvement in healthrelated quality of life using King's health questionnaire in non-obese and obese patients with lower urinary tract symptoms after alpha-adrenergic medication: a preliminary study. BMC Urology 2014 14:60.

\section{Submit your next manuscript to BioMed Central and take full advantage of:}

- Convenient online submission

- Thorough peer review

- No space constraints or color figure charges

- Immediate publication on acceptance

- Inclusion in PubMed, CAS, Scopus and Google Scholar

- Research which is freely available for redistribution 